\title{
TRENDS IN PREMATURE MORTALITY RATES AMONG THE POLISH POPULATION DUE TO CARDIOVASCULAR DISEASES
}

\section{WACŁAW MORYSON and BARBARA STAWIŃSKA-WITOSZYŃSKA}

\author{
Poznan University of Medical Sciences, Poznań, Poland \\ Department of Epidemiology and Hygiene, Chair of Social Medicine
}

\begin{abstract}
Objectives: At the end of the 20th century, after years of negligence in the prevention of cardiovascular diseases, Poland was struggling with very high premature mortality. The period of 1991-2005 brought significant improvements since the general public introduced beneficial dietary modifications. This paper aims to analyze the changes in the rate of premature mortality due to tobacco-dependent cardiovascular diseases in Poland in 2008-2017. Material and Methods: The time trends of deaths occurring under the age of 65 years caused by ischemic heart disease, cerebrovascular disease, atherosclerosis and aortic aneurysm were analyzed. Both standardized and crude premature mortality rates were used, as well as mortality rates for patients grouped into 5-year age ranges with a breakdown by gender. The joinpoint model was used to determine these time trends. Results: Premature mortality due to the analyzed cardiovascular diseases decreased linearly in 2008-2017. In the case of ischemic heart disease and cerebrovascular diseases, the decrease amounted to approx. 5\% per year, both in the female and male population. However, in the case of atherosclerosis and aortic aneurysms, the rate of mortality reduction ranged $4-7 \%$ per year. The reduction concerned all the examined age groups, but with different dynamics. The most considerable annual decrease was observed in the group of patients aged $40-44$ years (7.9\% for females and $8.9 \%$ for males). Along with the increase in age, the dynamics of reduction decreased. Conclusions: In 2008-2017, Poland experienced a decline in premature mortality due to tobacco-related cardiovascular diseases, particularly in the age group of $40-44$ years. The decline may have been associated, among other things, with a reduction in exposure to tobacco smoke, one of the cardiovascular risk factors. Int J Occup Med Environ Health. 2022;35(1):27-38
\end{abstract}

Key words:

Poland, mortality, premature mortality, cardiovascular diseases, tobacco smoke pollution, smoking reduction

\section{INTRODUCTION}

Cardiovascular diseases have been the main cause of death in Poland for many years. The mortality rate caused by these diseases is higher than in most EU countries and over the years has contributed to shorter life expectancy for women and men, compared to the average life expectancy in other highly developed countries [1].

Owing to the results of the Framingham Heart Study [2], the 1960s and 1970s brought the first reports on cardiovascular risk factors, and behavioral as well as the envi- ronmental ones [2]. In response to this, highly developed countries have begun to take measures leading to a decline in tobacco consumption and changes in eating habits, and thus, to a reduction in mortality from cardiovascular diseases [3]. Meanwhile, Poland pursued a policy of subsidizing tobacco products and animal food products, which kept both tobacco consumption rates and cardiovascular mortality rates on an upward trend [3].

In Poland, the increase in mortality rates caused by cardiovascular diseases lasted until the early 1990s, and the mor-

Received: November 26, 2020. Accepted: April 26, 2021

Corresponding author: Wacław Moryson, Poznan University of Medical Sciences, Department of Epidemiology and Hygiene, Chair of Social Medicine, Rokietnicka 4, 60-806 Poznań, Poland (e-mail: waclawmoryson@onet.eu). 
tality rate in the population of people aged 20-64 years was by then already twice as high as the average for their peers in the countries of the then European Union [4]. However, the 1990s brought a sharp decline in cardiovascular mortality. It was a time of rapid social and political changes in Poland, connected with the political transformation and the end of the communist period. The analyses concerning this unprecedented period and the impact of the decisions made at that time on the health situation of the Polish population emphasized the importance of changes in exposure to environmental and behavioral risk factors of cardiovascular diseases, and the effect they had on the decrease in cardiovascular mortality. More than half of the total mortality reduction in 1991-2005 was attributed to the decrease in exposure to modifiable risk factors, with particular emphasis on changes in the diet of Poles. During that period, the subsidization of food and tobacco products was discontinued, and the availability of fresh fruit and vegetables was increased by all-year-round imports [5].

At the beginning of the 21st century, after 4 decades of reducing mortality, a slowdown in the downward trend in the young population was observed in highly developed countries [6-8]. At the same time, there was a dramatic increase in the number of deaths from cardiovascular diseases in developing countries, affecting mainly people aged $40-59$ years [9].

In 2013, the World Health Organization (WHO) drew attention to the need to reduce premature mortality due to cardiovascular diseases, with a particular focus on reducing the exposure to behavioral and environmental risk factors. The target for 2013-2025 was to reduce at least $25 \%$ of premature deaths caused by cardiovascular diseases [10]. In the face of these global changes, further decisions were made in Poland in order to maintain the downward trend in mortality. In 2008, Poland ratified the MPOWER anti-smoking strategy to reduce both active and passive exposure to tobacco smoke. Within the framework of this program, among other things, in 2010, a general ban on smoking in public places was introduced in Poland [11]. The successive implementation of the solutions proposed by the WHO resulted in a decrease in the prevalence of nicotinism in Poland in 2008-2017 by $9.4 \%$ for men and by $16.7 \%$ for women, according to the Polish Central Sanitary Inspectorate [12].

This study aimed to analyze the changes in the level of premature mortality of males and females due to cardiovascular diseases in 2008-2017 in Poland.

\section{MATERIAL AND METHODS}

The presented paper analyzes all registered deaths of Polish residents aged $<65$ years in 2008-2017. The data concerning the number of deaths and the size of the population in age ranges come from Statistics Poland. The analysis includes deaths from selected cardiovascular diseases, where the mortality rate depends largely on the prevalence of smoking, based on Cancer Prevention Study II Nutrition Cohort [13]. The initial cause of death was classified according to the International Statistical Classification, Diseases and Health Problems (ICD-10) [14]. The time trends were determined for selected groups - ischemic heart disease (I20-I25), cerebrovascular disease (I60-I69), atherosclerosis (I70) and aortic aneurysm (I71) (Table 1).

Unfortunately, the mortality statistics for cardiovascular diseases in Poland in the years analyzed were characterized by the low quality of data, especially as regards cardiovascular diseases. In 2016, according to Statistics Poland and the National Institute of Public Health and Hygiene, almost half of all cardiovascular deaths (46.7\%) were related to the use of the so-called "garbage codes" defined by the WHO $[15,16]$. For this reason, the authors excluded the following from the analysis: rheumatic heart disease I00-I09, pulmonary heart disease and diseases of pulmonary circulation I26-I28, other heart diseases (I29-I51) and other arterial diseases (I72-I78). Pulmo- 
nary heart disease and heart failure were excluded because they are the consequences of the disease and not the underlying cause of death [17]. The inclusion of atherosclerosis, one of the most commonly misdiagnosed underlying causes of death in cardiovascular diseases, also in the population of young people, was to demonstrate the scale of the problem.

In the analysis of the mortality of the population of men and women aged $<65$ years, the mortality rates used were those standardized based on the standard European population of 2013 and crude mortality rates for age groups [18]. Mortality trends were determined for 5-year age groups (20-24, 25-29, 30-34, 35-39, 40-44, 45-49, $50-54,55-59$, and $60-64$ years of age) with a breakdown by gender.

In the determination of mortality time trends, the joinpoint model was used, i.e., a special version of linear regression presenting time trends by means of a broken curve, consisting of segments joining at points where a change in the time trend is significant. The analysis was conducted with the minimum number of 0 joinpoints (a straight line), followed by tests for model fit with a maximum of 1 joinpoint. The Monte Carlo permutation method for tests of significance was used. The homoscedasticity model was selected (errors are assumed to have constant variance). Using the Monte Carlo permutation technique with 4499 randomly selected data sets, the numbers and locations of the joinpoints, with the best-fitted models for mortality trend were estimated. When the single joinpoint model more accurately described the mortality trend, the location of the joinpoint on the timeline determined the year of the mortality trend change.

Based on the calculated models, the annual percentage change (APC) between points and the average APC over the whole analyzed period were determined for mortality rates [19]. The statistical software Joinpoint Regression v. 4.7.0.0 (the U.S. National Cancer Institute) was used to determine the regression models. Both for the APC
Table 1.The analyzed groups of cardiovascular diseases causing premature mortality in Poland in 2008-2017, according to ICD-10

Cardiovascular diseases causing premature mortality (ICD-10)

I20-I25 Ischemic heart disease

I20 Angina pectoris

121 Acute myocardial infarction

122 Subsequent myocardial infarction

I23 Complications following acute myocardial infarction

I24 0ther acute ischemic heart diseases

I25 Chronic ischemic heart disease

160-169 Cerebrovascular diseases

160 Subarachnoid haemorrhage

161 Intracerebral haemorrhage

I62 0ther nontraumatic intracranial haemorrhage

163 Cerebral infarction

I64 Stroke, not specified

1650 cclusion and stenosis of precerebral arteries,

not resulting in cerebral infarction

1660 cclusion and stenosis of cerebral arteries,

not resulting in cerebral infarction

1670 0ther cerebrovascular diseases

168 Cerebrovascular disorders in diseases classified elsewhere

169 Sequelae of cerebrovascular disease

170 Atherosclerosis

I71 Aortic aneurysm and dissection

between points and the average APC of the coefficients, 95\% confidence intervals (CI) were determined and $\mathrm{p}<0.05$ was taken as the significance level.

The study was reviewed and approved by the Ethics Committee of the Poznan University of Medical Sciences. No potentially identifiable human images or data are presented in this study.

\section{RESULTS}

In 2008, selected cardiovascular diseases caused 4473 premature deaths in females and 14554 premature deaths in males, which corresponded to $13.4 \%$ of all female premature deaths and $17.6 \%$ of all male premature deaths. The cardiovascular diseases with the highest impact on premature mortality among both women and men included ischemic heart disease $(10.5 \%$ and $5.9 \%$ of all premature deaths among men and women, respectively), 


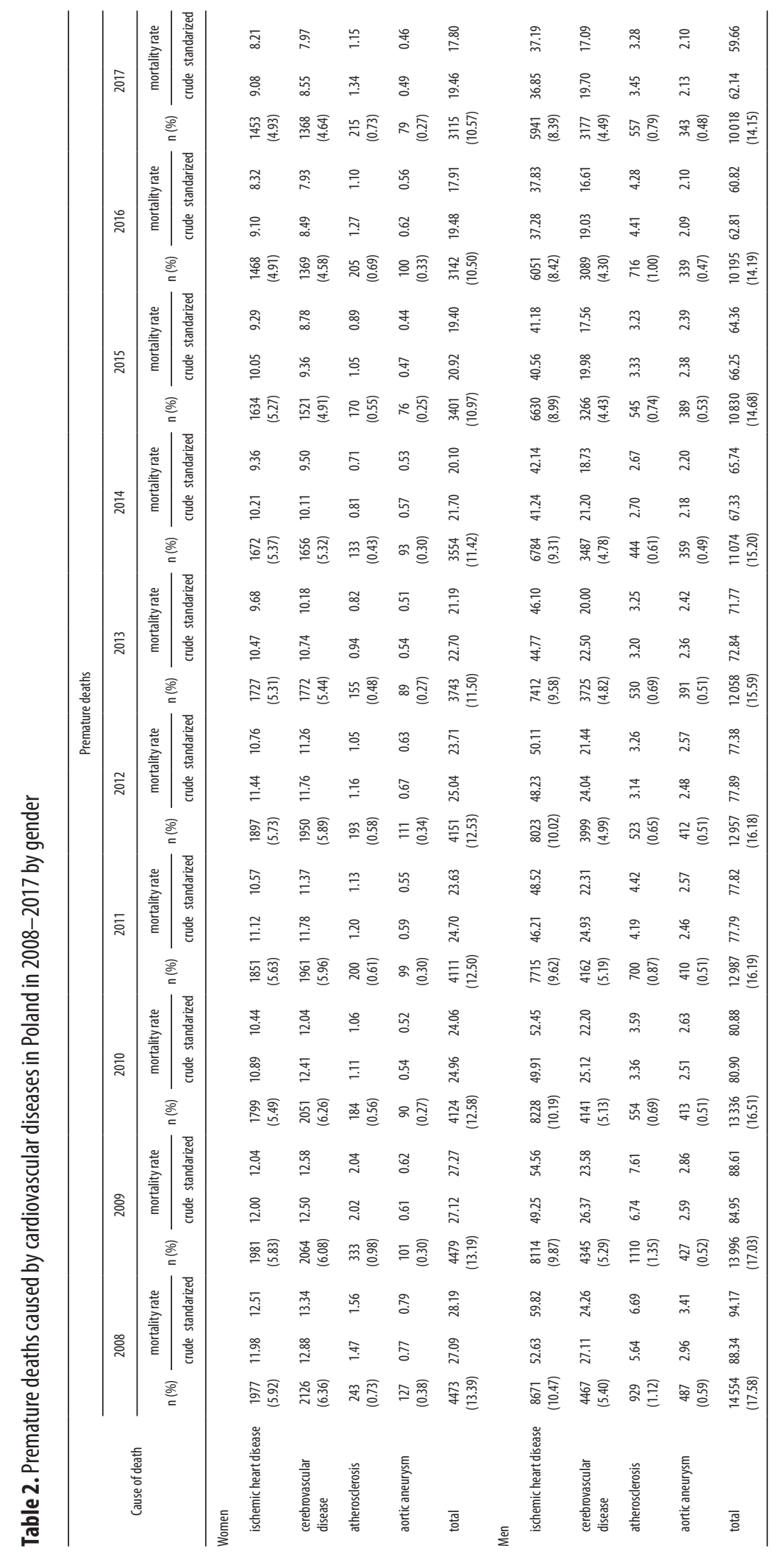


and cerebrovascular diseases (5.4\% of all premature deaths among men and 6.4\% among women) (Table 2). In the case of all analyzed diseases, the vast majority of premature deaths occurred at $>39$ years of age. Moreover, in all age groups, mortality rates were higher in the male population. Detailed data on mortality in particular age groups of males and females are presented in Table 3.

Premature mortality due to the above cardiovascular diseases decreased over the discussed period, both in men and women. The decrease was linear and amounted to $5.2 \%$ per year for women and $5 \%$ for men. The reduction of premature mortality due to particular groups and diseases was also linear. Premature mortality due to ischemic heart disease decreased by $4.4 \%$ for females and $5.1 \%$ for males per year. The annual decline in cerebrovascular mortality was similar, at $5.9 \%$ for females and $4.4 \%$ for males. Premature mortality due to atherosclerosis, on the other hand, decreased from year to year by $5.6 \%$ for females and $7.3 \%$ for males, whereas for aortic aneurysms by $3.9 \%$ and 5\%, respectively. All identified trends in standardized mortality rates, except for premature female mortality due to atherosclerosis, are statistically significant (Table 4).

Mortality due to the cardiovascular diseases under analysis decreased in all the examined age groups of female and male patients, although at different rates. The highest annual decrease in mortality was observed in the group of $40-44$ years of age, with $7.9 \%$ for females and $8.9 \%$ for males. With an increase in the age of the surveyed, the dynamics of mortality reduction decreased. However, even in the oldest group analyzed, i.e., those 60-64 years of age, it amounted from year to year to $4.7 \%$ for females and $4 \%$ for males (Table 4 ).

\section{Ischemic heart disease}

Both male and female mortality reduction rates were the highest in the age group of 30-44 years, with $11 \%$ for men and $10 \%$ for women per year. The dynamics of mortality reduction decreased in proportion to age.

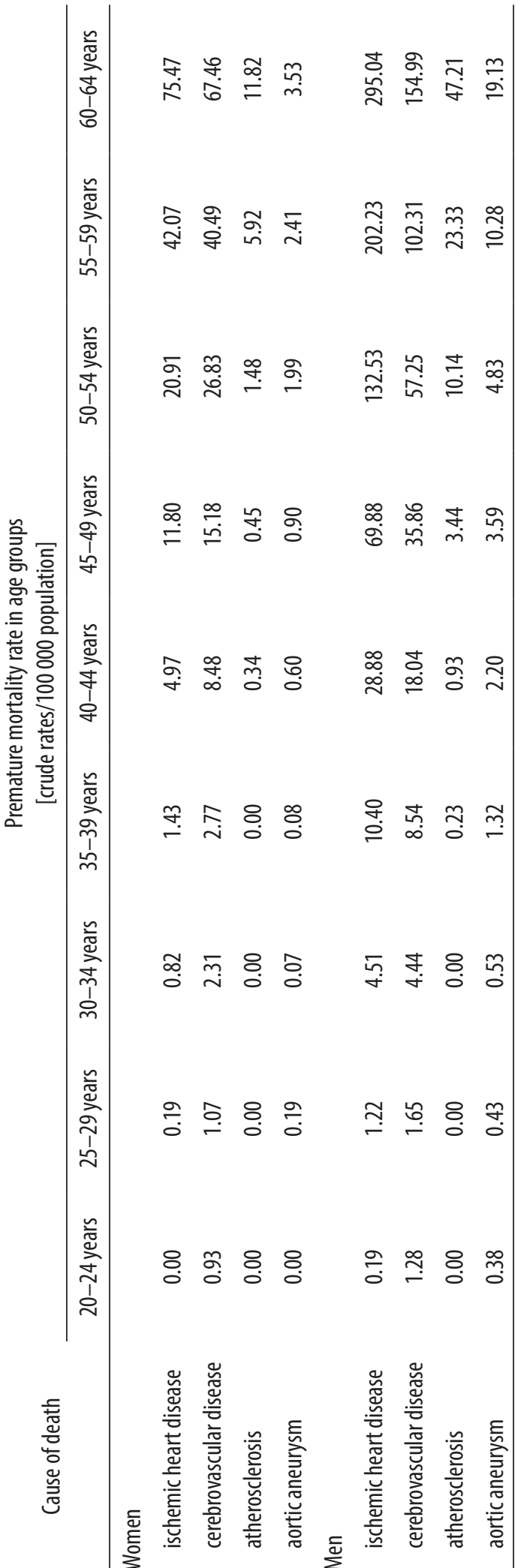

IJOMEH 2022;35(1) 
Table 4. Time trends of standardized mortality rates due to the analyzed cardiovascular diseases in Poland in 2008-2017

\begin{tabular}{|c|c|c|c|c|}
\hline \multirow{3}{*}{ Variable } & \multicolumn{4}{|c|}{ Time trends of standardized mortality rates } \\
\hline & \multicolumn{2}{|c|}{ women } & \multicolumn{2}{|c|}{ men } \\
\hline & $\operatorname{APC}(95 \% \mathrm{Cl})$ & AAPC (95\% Cl) & $\operatorname{APC}(95 \% \mathrm{Cl})$ & AAPC (95\% Cl) \\
\hline \multicolumn{5}{|l|}{ Cardiovascular disease } \\
\hline ischemic heart disease & $-4.4^{*}(-5.3-(-3.5))$ & $-4.4^{*}(-5.3-(-3.5))$ & $-5.1^{*}(-5.7-(-4.4))$ & $-5.1^{*}(-5.7-(-4.4))$ \\
\hline cerebrovascular disease & $-5.9 *(-6.6-(-5.2))$ & $-5.9 *(-6.6-(-5.2))$ & $-4.4^{*}(-5.1-(-3.7))$ & $-4.4^{*}(-5.1-(-3.7))$ \\
\hline atherosclerosis & $-5.6(-11.7-0.9)$ & $-5.6(-11.7-0.9)$ & $-7.3^{*}(-13.3-(-0.8))$ & $-7.3^{*}(-13.3-(-0.8))$ \\
\hline aortic aneurysm & $-3.9^{*}(-6.9-(-0.9))$ & $-3.9^{*}(-6.9-(-0.9))$ & $-4.5^{*}(-5.8-(-3.1))$ & $-4.5^{*}(-5.8-(-3.1))$ \\
\hline total & $-5.2^{*}(-5.9-(-4.5))$ & $-5.2^{*}(-5.9-(-4.5))$ & $5.0^{*}(-5.6-(-4.4))$ & $5.0^{*}(-5.6-(-4.4))$ \\
\hline \multicolumn{5}{|l|}{ Age } \\
\hline $20-24$ years & $-2.4(-11.2-7.2)$ & $-2.4(-11.2-7.2)$ & $-3.7(-9.5-2.4)$ & $-3.7(-9.5-2.4)$ \\
\hline $25-29$ years & $-5.0^{*}(-9.5-(-0.2))$ & $-5.0^{*}(-9.5-(-0.2))$ & $-3.6(-7.8-0.9)$ & $-3.6(-7.8-0.9)$ \\
\hline $30-34$ years & $-5.7^{*}(-9.6-(-1.7))$ & $-5.7^{*}(-9.6-(-1.7))$ & $-5.3^{*}(-8.4-(-2.0))$ & $-5.3^{*}(-8.4-(-2.0))$ \\
\hline $35-39$ years & $-3.8^{*}(-7.1-(-0.2))$ & $-3.8^{*}(-7.1-(-0.2))$ & $-7.9 *(-9.7-(-6.1))$ & $-7.9^{*}(-9.7-(-6.1))$ \\
\hline $40-44$ years & $-7.9^{*}(-10.0-(-5.7))$ & $-7.9^{*}(-10.0-(-5.7))$ & $-8.9^{*}(-10.2-(-7.7))$ & $-8.9 *(-10.2-(-7.7))$ \\
\hline $45-49$ years & $-5.8^{*}(-8.4-(-3.1))$ & $-5.8^{*}(-8.4-(-3.1))$ & $-7.0^{*}(-8.1-(-5.8))$ & $-7.0^{*}(-8.1-(-5.8))$ \\
\hline $50-54$ years & $-6.6^{*}(-7.8-(-5.4))$ & $-6.6^{*}(-7.8-(-5.4))$ & $-6.1^{*}(-6.6-(-5.5))$ & $-6.1^{*}(-6.6-(-5.5))$ \\
\hline $55-59$ years & $-4.7^{*}(-5.9-(-3.5))$ & $-4.7^{*}(-5.9-(-3.5))$ & $-5.3^{*}(-5.9-(-4.7))$ & $-5.3^{*}(-5.9-(-4.7))$ \\
\hline $60-64$ years & $-4.7^{*}(-5.4-(-3.9))$ & $-4.7^{*}(-5.4-(-3.9))$ & $-4.0^{*}(-4.8-(-3.2))$ & $-4.0^{*}(-4.8-(-3.2))$ \\
\hline
\end{tabular}

AAPC - average annual percentage change; APC - annual percentage change.

${ }^{*}$ The significant values were marked at $p<0.05$.

In the oldest groups analyzed, i.e., 55-64 years of age, the decrease in the mortality rate was $4 \%$ per year. All identified mortality trends for groups $>30$ years of age were statistically significant (Table 5).

\section{Cerebrovascular diseases}

The decline in mortality in both sexes in all age groups was similar to that of the entire population of people aged $<65$ years (6\% per year for women and 5\% for men). The mortality trends for women aged $>40$ years and men aged $>35$ years were statistically significant (Table 5 ).

\section{Atherosclerosis}

The diagnosis of atherosclerosis as the cause of death occurred mostly in the 2 oldest age groups, $92 \%$ of pre- mature deaths due to atherosclerosis referred to people aged $>55$ years. Mortality reduction was observed in all age groups. It was higher in younger groups, reaching $20 \%$ per year, and decreased with age, reaching $3 \%$ in females and $2 \%$ in males per year among the patients aged 60-64 years. Only the trends observed among males aged 45-54 years were statistically significant (Table 5).

\section{Aortic aneurysm}

A decrease in mortality rates was observed in all age groups, with the exception of males aged 30-34 years and females aged 45-49 years, among whom the mortality due to aortic aneurysm remained unchanged. Among men, these trends were statistically significant 


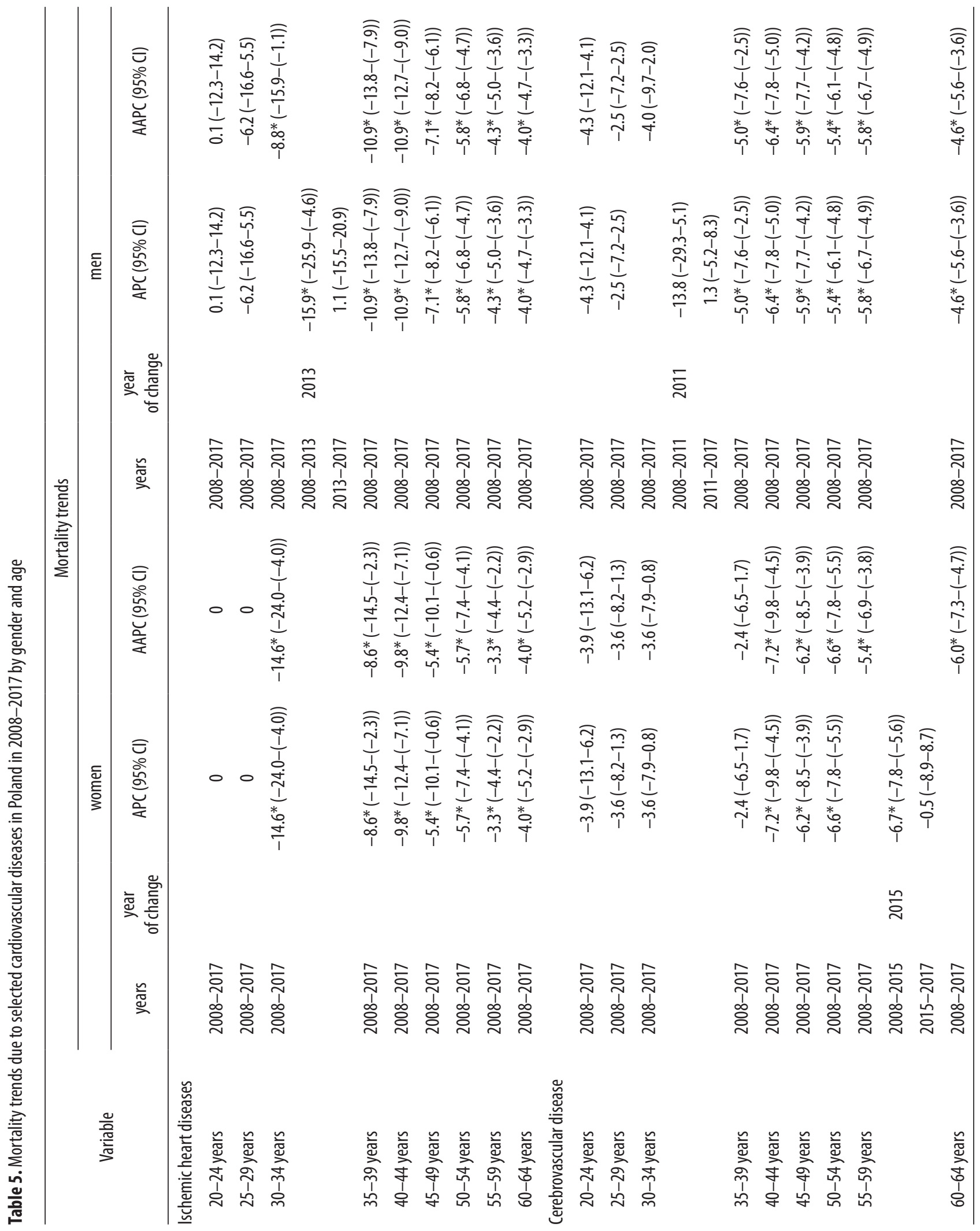




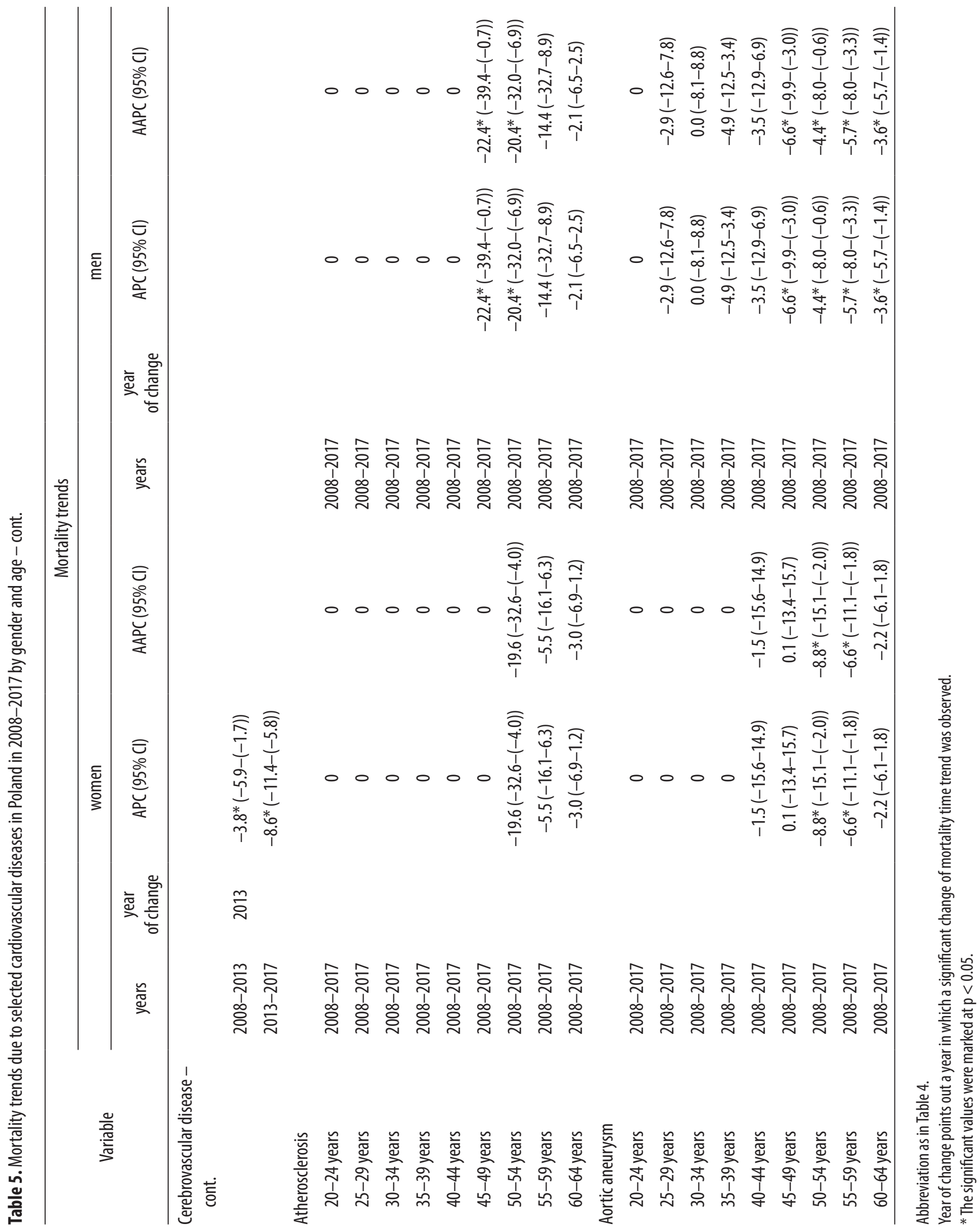


for all males aged $>45$ years, whereas among females the statistical significance pertained only to those aged 50-59 years (Table 5 ).

\section{DISCUSSION}

Among the former Eastern Bloc states, Poland is the largest member of the EU. The county has been classified by the World Bank as a high income economy since 2009 [20]. Polish economy has been growing steadily since 1992 resulting in the country's 7-fold increase in gross domestic product (GDP) [21]. In 2017, the GDP per capita in Poland amounted to $70 \%$ of the EU average [22].

In Poland, the decade 2008-2017 saw a reduction in premature mortality caused by the analyzed cardiovascular diseases by nearly $37 \%$, both among males and females. The observed dynamics significantly exceeded the rate of reduction of premature mortality due to cardiovascular diseases, estimated by the WHO for 2013-2025 at $25 \%$ [10].

The highest mortality rates were observed in the case of ischemic heart disease and cerebrovascular diseases. The level of reduction of premature mortality due to these 2 diseases oscillated around 5\% per year, both in the female and male populations. In the case of atherosclerosis and aortic aneurysms, the diseases responsible for a much lower number of premature deaths, the rate of mortality reduction ranged $4-7 \%$ per year.

In the case of cerebrovascular diseases and aortic aneurysm, a similar rate of mortality reduction was observed in all age groups, whereas in the case of ischemic heart disease and atherosclerosis the reduction of mortality was higher in the younger age groups. This situation corresponds with the model of decreasing cardiovascular mortality in highly developed countries in the 1980s. At the beginning of the 21st century, in Great Britain, the United States and Australia, a decrease in the reduction of cardiovascular mortality among younger people was observed [6-8].
At the end of the analyzed period, the epidemiological situation of Poland in terms of mortality from cardiovascular diseases was completely different than it was at the beginning of the 1990s. In the 25 -year period since the beginning of the political transformation, Poland has transitioned to a country in which mortality rates, both due to ischemic heart disease and cerebrovascular diseases, have reached the level of the European average [23]. This positive phenomenon was associated with changes in exposure to risk factors that began in the early 1990s. The results of the IMPACT study indicated the complex nature of the changes affecting the reduction in mortality from coronary heart disease in 1991-2005 in Poland. However, those results highlighted the greatest importance of the reduction in blood cholesterol levels due to dietary modifications and the introduction of new treatment methods [5].

This work is designed as a descriptive epidemiological study. It aims to describe the trends in premature mortality due to cardiovascular diseases in Poland. The methodology used does not make it possible to show the cause-and-effect correlation between any risk factors and reduced premature mortality. However, the results of the above analysis indicate that the subsequent preventive health care decisions in Poland have ensured the continuation of the downward trend in premature mortality due to cardiovascular diseases observed since the early 1990s. Cigarette smoking is one of the most important risk factors for cardiovascular diseases whose changes have been observed in Poland over the past 25 years [24].

In 1994, Lopez [25] described a model of the nicotinism epidemic according to which the effect of a change in nicotinism prevalence in a population is reflected in nicotinism-related mortality with a time lag of several decades. Thus, due to the different course of the nicotinism epidemic in Poland, in comparison with Western European countries and other developed countries where a decrease in the number of smokers had already taken 
place in the 1960s, a reduction in the prevalence of nicotinism took place only in the second half of the 1990s, i.e., about 20 years before the period covered by this study [26]. In 1996-2014, the proportion of daily smokers in Poland decreased from 31.5\% to 22.7\% [24]. In addition, the current smoke-free policy in Poland, based on the WHO MPOWER strategy, contributed to a further decrease in the proportion of daily smokers by $9.4 \%$ for men and $16.7 \%$ for women in 2009-2017, and to a significant reduction in passive exposure to tobacco smoke in public places [12].

Poland, due to its similar geographic location and a similar history of being part of the Eastern Bloc, is considered within a group of countries such as Bulgaria, Croatia, the Czech Republic, Estonia, Latvia, Lithuania, Romania, Hungary and Slovakia in the analyses on the subject of cardiovascular mortality worldwide [27]. Many of these countries continue to exhibit the highest cardiovascular mortality rates in the world [28]. The authors of the aforementioned analyses indicate a growing disproportion in mortality from cardiovascular diseases between the former Eastern Bloc countries and Western European countries [29]. In this respect, a significant change seems to be worth emphasizing, concerning the mortality from cardiovascular diseases in Poland and the difference in mortality due to the analyzed diseases among the countries of the former Eastern Bloc.

The described reduction in premature mortality did not result in a significant decrease in the percentage of people dying from cardiovascular diseases in Poland. Cardiovascular diseases are still the most common cause of death, accounting for $48.8 \%$ of female and $38.2 \%$ of male deaths. The decline in premature mortality contributed to the increase in the life expectancy of Polish citizens in 19912016 by 4 years for males and 4.3 years for females [1]. In 2015, the values of standardized mortality rates for ischemic heart disease and cerebrovascular disease were closer to Western European countries such as France, Germany or Spain, than to the former Eastern Bloc countries such as Hungary, Estonia or Slovakia [28].

In the early 1990s, after years of neglecting the prevention of cardiovascular diseases, having experienced high mortality rates from those diseases, Poland was facing a much more difficult challenge to reduce premature mortality than Western European countries did. In the early 1990s, the mortality rate due to cardiovascular diseases in Poland, both for females and males aged 20-64, more than doubled the average observed in the 15 states that comprised the EU in 1995-2004 [4]. The dynamic decline in mortality due to beneficial social and organizational changes in the health care system resulted in such a significant decline in mortality since the early 1990s that in 2015 Poland's mortality rate caused by ischemic heart disease and cerebrovascular disease (the most common cardiovascular causes of mortality) was at the level of the European Union average [23]. The effective implementation of further solutions, such as anti-smoking measures, expressed as a further reduction of premature mortality, makes it possible for Poland to easily implement the WHO recommended reduction of premature mortality related to cardiovascular diseases.

\section{CONCLUSIONS}

In 2008-2017, Poland experienced a decrease in premature mortality due to ischemic heart disease, cerebrovascular diseases, atherosclerosis and aortic aneurysm, especially in the youngest age group of 40-44 years, which may be associated, among other things, with a reduction in exposure to smoking as one of the risk factors for cardiovascular diseases.

The reduction in premature mortality due to atherosclerosis may result from improving the quality of an assessment of the root cause of death in Poland by physicians as well as recording the correct codes of 
the root cause of death instead of using the "garbage codes."

\section{REFERENCES}

1. Wojtyniak B, Goryński P. [Sytuacja zdrowotna ludności Polski i jej uwarunkowania]. Warsaw: National Institute of Public Health - National Institute of Hygiene; 2018. Polish.

2. Kannel WB. Factors of Risk in the Development of Coronary Heart Disease - Six-Year Follow-up Experience: The Framingham Study. Ann Intern Med. 1961;55:33, https://doi.org/ 10.7326/0003-4819-55-1-33.

3. Kesteloot H, Sans S, Kromhout D. Dynamics of cardiovascular and all-cause mortality in Western and Eastern Europe between 1970 and 2000. Eur Heart J. 2006;27:107-13, https://doi.org/10.1093/eurheartj/ehi511.

4. Manczuk M, Sulkowska U, Zatonski WA. Closing the health gap in European Union. Warsaw: Cancer Epidemiology and Prevention Division, the Maria Skłodowska-Curie Memorial Cancer Center and Institute of Oncology; 2008.

5. Bandosz P, O'Flaherty M, Drygas W, Rutkowski M, Koziarek J, Wyrzykowski B, et al. Decline in mortality from coronary heart disease in Poland after socioeconomic transformation: modelling study. BMJ. 2012;344:d8136, https://doi. org/10.1136/bmj.d8136.

6. Mensah GA, Wei GS, Sorlie PD, Fine LJ, Rosenberg Y, Kaufman PG, et al. Decline in Cardiovascular Mortality: Possible Causes and Implications. Circ Res. 2017;120:366-80, https:// doi.org/10.1161/CIRCRESAHA.116.309115.

7. O'Flaherty M, Allender S, Taylor R, Stevenson C, Peeters A, Capewell S. The decline in coronary heart disease mortality is slowing in young adults (Australia 1976-2006): A time trend analysis. Int J Cardiol. 2012;158:193-8, https://doi.org/ 10.1016/j.ijcard.2011.01.016.

8. Allender S, Scarborough P, O'Flaherty M, Capewell S. Patterns of coronary heart disease mortality over the 20th century in England and Wales: Possible plateaus in the rate of decline. BMC Public Health. 2008;8:148, https://doi.org/ 10.1186/1471-2458-8-148.

9. Jagannathan R, Patel SA, Ali MK, Narayan KMV. Global Updates on Cardiovascular Disease Mortality Trends and Attribution of Traditional Risk Factors. Curr Diab Rep. 2019;19:44, https://doi.org/10.1007/s11892-019-1161-2.

10. World Health Organization [Internet]. Geneva: The Organization; 2013 [cited 2020 Jun 17]. Global action plan for the prevention and control of noncommunicable diseases: 2013-2020. Available from: http://apps.who.int/iris/bitstre am/10665/94384/1/9789241506236_eng.pdf.

11. World Health Organization. WHO report on the global tobacco epidemic, 2019: Offer help to quit tobacco use. Geneva: World Health Organization; 2019.

12. Trząsalska A, Staszyńska M, Krassowska U. [Raport z ogólnopolskiego badania ankietowego na temat postaw wobec palenia tytoniu]. Warsaw: Chief Sanitary Inspector; 2017. Polish.

13. National Center for Chronic Disease Prevention and Health Promotion (US) Office on Smoking and Health [Internet]. The Health Consequences of Smoking - 50 Years of Progress: A Report of the Surgeon General. Atlanta, GA: Centers for Disease Control and Prevention (US); 2014 [cited 2019 Jun 24]. Available from: http://www.ncbi.nlm.nih.gov/ books/NBK179276/.

14. World Health Organization. ICD-10: International statistical classification of diseases and related health problems. Geneva: World Health Organization; 2011.

15. Statistics Poland [Internet]. Warsaw: Statistics Poland; 2020 [cited 2020 Jul 26]. Zgony według przyczyn określanych jako "garbage codes". Available from: https://stat.gov.pl/obszary-tematyczne/ludnosc/statystyka-przyczyn-zgonow/ zgony-wedlug-przyczyn-okreslanych-jako-garbage-codes, 3,3.html. Polish.

16. World Health Organization Department of Health Statistics and Information Systems. WHO methods and data sources for global causes of death 2000-2011. Geneva: World Health Organization; 2013.

17. Stawińska-Witoszyńska B, Gałęcki J, Wasilewski W. Poradnik szkoleniowy dla lekarzy orzekających o przyczynach 
zgonów i wystawiających kartę zgonu. Warsaw: National Institute of Public Health - National Institute of Hygiene; 2019. Polish

18. Pace M, Lanzieri G, Glickman M, Grande E, Zupanic T, Wojtyniak B, et al. Revision of the European Standard Population: report of Eurostat's task force: 2013 edition. Luxembourg: Publications Office; 2013.

19. Yu B, Huang L, Tiwari RC, Feuer EJ, Johnson KA. Modelling population-based cancer survival trends by using join point models for grouped survival data. J Royal Stat Soc. 2009;172:405-25, https://doi.org/10.1111/j.1467-985X.2009. 00580.x

20. The World Bank [Internet]. Washington: The Bank; 2021 [cited 2021 Mar 6]. The World by Income and Region. Available from: https://datatopics.worldbank.org/world-developmentindicators/the-world-by-income-and-region.html.

21. The World Bank [Internet]. Washington: The Bank; 2021 [cited 2021 Mar 6]. GDP growth (annual \%) - Poland. Available from: https://data.worldbank.org/indicator/ NY.GDP.MKTP.KD.ZG?locations=PL.

22. Borek D, Morytz-Balska E, Gustyn J. Poland in the European Union: a statistical portrait. Warsaw: Statistics Poland; 2019.

23. Organisation for Economic Co-operation and Development. Health at a glance: Europe 2018: state of health in the EU cycle. Paris: The Organisation; 2018, https://doi. org/10.1787/health_glance_eur-2018-en.
24. Organisation for Economic Co-operation and Development [Internet]. Paris: The Organisation; 2021 [cited 2021 Mar 6]. Daily smokers. Available from: https://www.oecdilibrary.org/social-issues-migration-health/daily-smokers/ indicator/english_1ff488c2-en.

25. Lopez AD, Collishaw NE, Piha T. A descriptive model of the cigarette epidemic in developed countries. Tobacco Control. 1994;3:242-7, https://doi.org/10.1136/tc.3.3.242.

26. World Health Organization. The current status of the tobacco epidemic in Poland. Copenhagen: The Organization; 2009.

27. Movsisyan NK, Vinciguerra M, Medina-Inojosa JR, LopezJimenez F. Cardiovascular Diseases in Central and Eastern Europe: A Call for More Surveillance and Evidence-Based Health Promotion. Ann Glob Health. 2020;86:21, https:// doi.org/10.5334/aogh.2713.

28. Timmis A, Townsend N, Gale C, Grobbee R, Maniadakis N, Flather M, et al. European Society of Cardiology: Cardiovascular Disease Statistics 2017. Eur Heart J. 2018;39:508-79, https://doi.org/10.1093/eurheartj/ehx628.

29. Hartley A, Marshall DC, Salciccioli JD, Sikkel MB, Maruthappu M, Shalhoub J. Trends in Mortality From Ischemic Heart Disease and Cerebrovascular Disease in Europe: 1980 to 2009. Circulation. 2016;133:1916-26, https://doi. org/10.1161/CIRCULATIONAHA.115.018931.

This work is available in Open Access model and licensed under a Creative Commons Attribution-NonCommercial 3.0 Poland License - http://creativecommons.org/ licenses/by-nc/3.0/pl/deed.en. 